\title{
THREE-DIMENSIONAL MAGNETOSPHERIC EQUILIBRIUM WITH ISOTROPIC PRESSURE
}

\author{
BY
}

C.Z. CHENG

MAY 1995
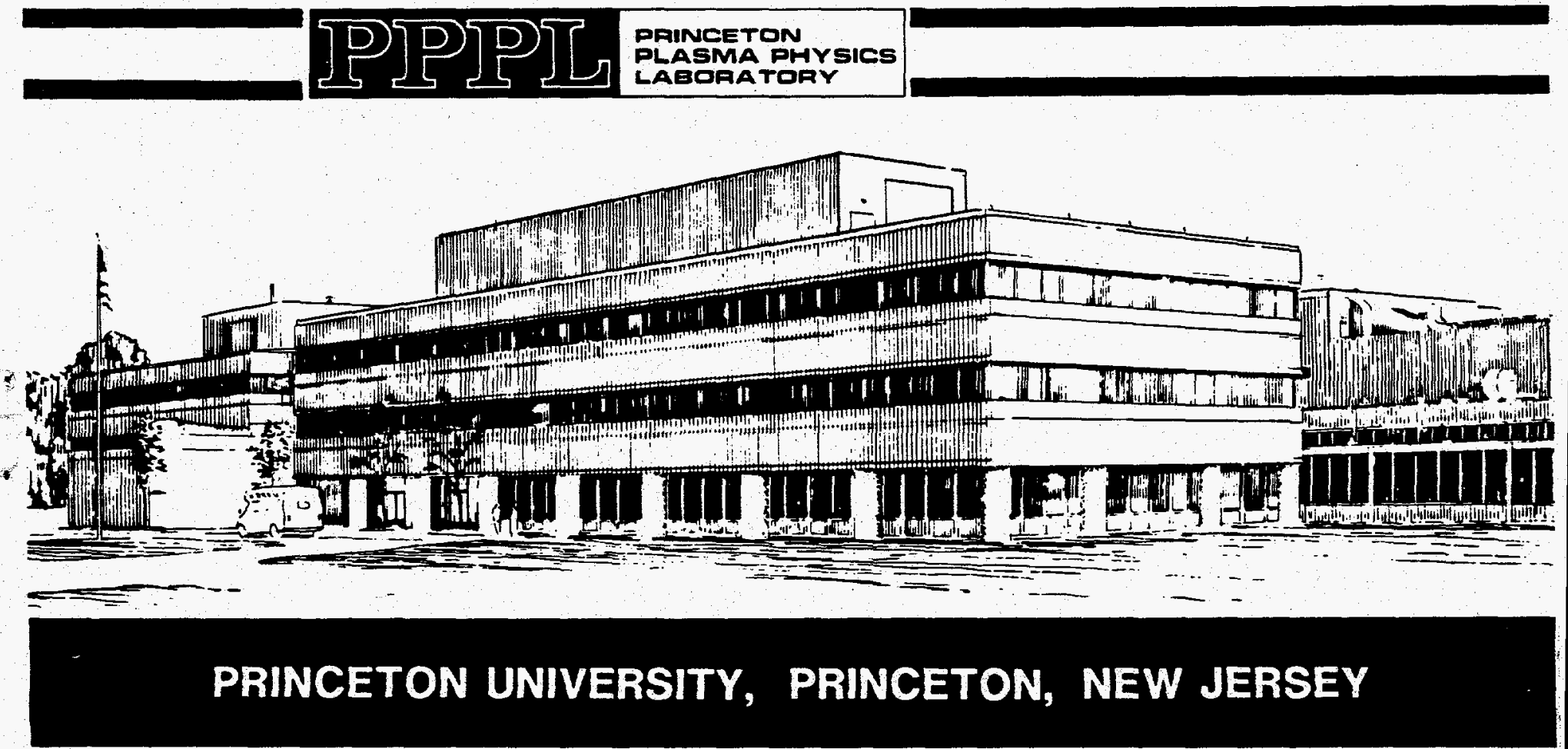


\section{NOTICE}

This report was prepared as an account of work sponsored by an agency of the United States Government. Neither the United States Government nor any agency thereof, nor any of their employees, makes any warranty, express or implied, or assumes any legal liability or responsibility for the accuracy, completeness, or usefulness of any information, apparatus, product, or process disclosed, or represents that its use would not infringe privately owned rights. Reference herein to any specific commercial produce, process, or service by trade name, trademark, manufacturer, or otherwise, does not necessarily constitute or imply its endorsement, recommendation, or favoring by the United States Government or any agency thereof. The views and opinions of authors expressed herein do not necessarily state or reflect those of the United States Government or any agency thereof.

\section{NOTICE}

This report has been reproduced from the best available copy. Available in paper copy and microfiche.

Number of pages in this report: 15

DOE and DOE contractors can obtain copies of this report from:

Office of Scientific and Technical Information

P.O. Box 62

Oak Ridge, TN 37831;

(615) $576-8401$.

This report is publicly available from the:

National Technical Information Service

Department of Commerce

5285 Port Royal Road

Springfield, Virginia 22161

(703) $487-4650$ 


\section{DISCLAIMER}

Portions of this document may be illegible in electronic image products. Images are produced from the best available original document. 


\title{
Three-Dimensional Magnetospheric Equilibrium with Isotropic Pressure
}

By

\section{Z. Cheng}

Princeton Plasma Physics Laboratory

Princeton University

P. O. Box 451, Princeton, New Jersey 08543

\begin{abstract}
In the absence of the toroidal flux, two coupled quasi two-dimensional elliptic equilibrium equations have been derived to describe self-consistent three-dimensional static magnetospheric equilibria with isotropic pressure in an optimal $(\psi, \alpha, \chi)$ flux coordinate system, where $\psi$ is the magnetic flux function, $\chi$ is a generalized poloidal angle, $\alpha=\phi-\delta(\psi, \phi, \chi), \phi$ is the toroidal angle, $\delta(\psi, \phi, \chi)$ is periodic in $\phi$, and the magnetic field is represented as $\overrightarrow{\mathrm{B}}=\nabla \psi \times \nabla \alpha$. A threedimensional magnetospheric equilibrium code, the MAG-3D code, has been developed by employing an iterative metric method. The main difference between the three-dimensional and the two-dimensional axisymmetric solutions is that the field-aligned current and the toroidal magnetic field are finite for the three-dimensional case, but vanish for the two-dimensional axisymmetric case. With the same boundary flux surface shape, the two-dimensional axisymmetric results [Cheng, 1992] are similar to the three-dimensional magnetoshere at each local time cross section.
\end{abstract}




\section{Introduction}

The problem of computing self-consistent high- $\beta\left(\beta=2 P / B^{2}\right.$, where $P$ is the plasma pressure and $B$ is the magnetic field intensity), static magnetospheric equilibria has attracted much attention from the early days of space physics research [Akasofu and Chapman, 1961]. Numerical as well as analytical solutions of general high- $\beta(\beta \geq 1)$ axisymmetric magnetospheric equilibria with anisotropic pressures has been performed [Cheng, 1992] by integrating the Grad-Shafranov equation with prescribed boundary flux shapes. Numerical studies have been performed to examine the effects of plasma $\beta$, pressure anisotropy, and boundary condition on the axisymmetric magnetospheric equilibrium. The results agree very well qualitatively with satellite observations of the ring current distribution and the magnetic field intensity within about $10 R_{E}$. This successful method is now extended to study three-dimensional high- $\beta$ magnetospheric equilibria.

An intrinsic feature of the three-dimensional magnetospheric structure is the existence of Birkeland currents, which are field-aligned currents linking the Earth's polar ionosphere with more distant magnetospheric plasma. Observations [Iijima and Potemra, 1976a,b] indicate that near Earth they flow in broad sheets, roughly aligned with the aurora oval. Those sheets form two large current systems, region 1 entering on the morning side of the polar cap and flowing out on the afternoonside, and region 2 further equatorward but with opposite polarities. At noon and midnight the current systems overlap in complicated ways, and during substorms region 1 on the nightside is reenforced by a "substorm wedge", which covers a limited sector in longitude. It is now generally considered that the region 2 currents originate from particle drift motion in the closed field line region [Schindler and Birn, 1978] where the plasma convective flow is slow in comparison with the thermal speeds. The sources of the region 1 currents are less clear and are still being actively debated: on the dayside they come from open field lines, and on the nightside they could come from the plasma sheet. Mathematical expressions for obtaining the field-aligned currents have been derived [Vasylinuas, 1970; Heinemann and Pontius, 1990; Birmingham, 1992]. However, quantitative studies of the self-consistent field-aligned currents have not been performed due to the lack of self-consistent three-dimensional magnetospheric equilibrium solutions.

The purpose of this paper is to provide numerical equilibrium solutions of the selfconsistent three-dimensional magnetic field and current structure of the magnetosphere with isotropic pressure. By assuming that the toroidal flux is zero (or, equivalently, no average toroidal magnetic field over the toroidal direction), the three-dimensional magnetospheric equilibrium equations can be reduced to two coupled quasi two-dimensional equations in an optimal flux 
coordinate system. A three-dimensional magnetospheric equilibrium code, the MAG-3D code, has been developed by employing an iterative metric method subject to boundary conditions of $\alpha$ and $\psi$ on the computational domain surrounded by the specified shapes of the inner and outer flux surfaces [Cheng, 1992]. Equations describing the current system are presented. The main difference between the three-dimensional and the two-dimensional axisymmetric solutions is that the field-aligned current and the toroidal magnetic field are finite for the three-dimensional case, but vanish for the two-dimensional axisymmetric case. The flux surfaces of the three-dimensional magnetoshere at each local time cross section are similar to the previous two-dimensional axisymmetric results [Cheng, 1992] with the same boundary flux surface shapes.

\section{Three-Dimensional Magnetospheric Equilibrium Equations and Current System}

If the plasma convection in the magnetosphere is small, the static magnetospheric equilibrium with isotropic pressure is described in the rationalized EMU unit by the system of equations: the force balance equation $\overrightarrow{\mathrm{J}} \times \overrightarrow{\mathrm{B}}=\nabla \mathrm{P}, \nabla \times \overrightarrow{\mathrm{B}}=\overrightarrow{\mathrm{J}}$, and $\nabla \cdot \overrightarrow{\mathrm{B}}=0$, where $\mathrm{P}$ is the plasma pressure. If the three-dimensional magnetospheric equilibrium has nested magnetic surfaces, the magnetic field can be expressed in a straight field line $(\psi, \alpha, \chi)$ flux coordinate as $\overrightarrow{\mathrm{B}}=$ $\nabla \psi \times \nabla \alpha$, where $\psi$ is the magnetic flux function, $\alpha=\zeta-\mathrm{q}(\psi) \chi, \zeta=\phi-\delta(\psi, \phi, \chi), \chi$ is a generalized poloidal angle, $\phi$ is the toroidal angle in the cylindrical $(\mathrm{R}, \phi, \mathrm{Z})$ coordinate, and $\delta(\psi, \phi, \chi)$ is periodic in both $\chi$ and $\phi$ so that $\overrightarrow{\mathrm{B}} \bullet \nabla \zeta / \overrightarrow{\mathrm{B}} \bullet \nabla \chi=\mathrm{q}(\psi)$. The intersection of surfaces of constant $\psi$ and $\alpha$ defines the magnetic field line. The Jacobian is given by $\boldsymbol{J}=(\nabla \psi \times \nabla \zeta \bullet \nabla \chi)^{-1}$. The flux coordinate system is in general not orthogonal because $\nabla \psi \bullet \nabla \chi \neq 0, \nabla \psi \bullet \nabla \zeta \neq 0$, and $\nabla \zeta \bullet \nabla \chi \neq 0$. Within a magnetic surface the poloidal flux is $\Psi=(1 / 2 \pi) \int \mathrm{d}^{3} \times \vec{B} \bullet \nabla \chi=2 \pi \psi$, and the toroidal flux is $\Phi=(1 / 2 \pi) \int d^{3} \times \vec{B} \bullet \nabla \zeta$. We will choose $q(\psi)=0$ so that $\alpha=\zeta$ and $\Phi=0$. Then, $\alpha$ is a cyclic function with a period of $2 \pi$ for all constant $\psi$ surfaces. This property allows to reduce the general three-dimensional equilibrium equations to quasi two-dimensional equations in the flux coordinate system, and thus greatly simplfies the computational complexity.

Since $\vec{B} \bullet \nabla P=0$, the pressure is constant along the field line. If the particle drift surfaces coincide with the constant $\psi$ surfaces, $\mathrm{P}$ is a function of $\psi$ only. The $\overrightarrow{\mathrm{B}} \times \nabla \psi$ component of the force balance equation gives the radial current density,

$$
\overrightarrow{\mathbf{J}} \cdot \nabla \psi=\nabla \cdot\left[(\nabla \psi)^{2} \nabla \alpha-(\nabla \alpha \cdot \nabla \psi) \nabla \psi\right]=0,
$$


which is a two-dimensional elliptic equation on each constant $\psi$ surface. Note that in the twodimensional axisymmetric limit, Eq.(1) is trivially satisfied by $\alpha=\phi$. The $\nabla \psi$ component of the momentum equation gives the ring current and the generalized Grad-Shafranov equation,

$$
\overrightarrow{\mathrm{J}} \cdot \nabla \alpha=\nabla \cdot\left[(\nabla \alpha \bullet \nabla \psi) \nabla \alpha-(\nabla \alpha)^{2} \nabla \psi\right]=\mathrm{dP} / \mathrm{d} \psi
$$

which is a two-dimensional elliptic equation on each constant $\alpha$ surface. Note that in general Eqs.(1) and (2) are three-dimensional equations. However, by choosing the $(\psi, \alpha, \chi)$ coordinate system we have reduced the dimensionality of Eqs. (1) and (2) from three-dimensional differential equations to quasi two-dimensional differential equations. Equations (1) and (2) form a coupled set of equations that determine $\alpha$ and $\psi$, and can be solved by specifing $\alpha$ and $\psi$ on the computational boundary as well as the functional form of $\mathrm{P}(\psi)$.

From the charge neutrality condition, $\nabla \cdot \overrightarrow{\mathbf{J}}=0$, the field-aligned current density equation can be computed from

$$
\overrightarrow{\mathrm{B}} \bullet \nabla\left(\mathrm{J}_{\|} / \mathrm{B}\right)=2 \overrightarrow{\mathrm{K}} \times \overrightarrow{\mathrm{B}} \bullet \nabla \mathrm{P} / \mathrm{B}^{2}=\nabla \mathrm{B}^{2} \times \overrightarrow{\mathrm{B}} \bullet \nabla \mathrm{P} / \mathrm{B}^{4},
$$

where $J_{\|}$is the field-aligned current density, $\vec{k}=\widehat{b} \bullet \nabla \widehat{b}$ is the magnetic field curvature, and $\widehat{b}$ is a unit vector along a magnetic field line. The field-aligned current density can be obtained by integrating Eq. (3) along the field line. The right hand sides of Eq. (3) represent the source of the field-aligned current density which originates from the particle guiding-center $\nabla \mathrm{B}$ and curvature drifts across the pressure gradient. For axisymmetric case, $\vec{\kappa} \times \vec{B}$ is in the $\nabla \phi$ direction, the right hand side of Eq. (3) is zero, and hence $\mathrm{J}_{\|}=0$ everywhere.

Alternatively, the current density can be expressed in a differential form [Shafranov, 1968; Heinemann and Pontius, 1990] and is given by

$$
\overrightarrow{\mathbf{J}}=\nabla \mathrm{V} \times \nabla \mathrm{P}+\mathrm{g} \overrightarrow{\mathrm{B}}=\nabla \psi \times[\mathrm{g} \nabla \alpha-(\mathrm{dP} / \mathrm{d} \psi) \nabla \mathrm{V}]
$$

where $\mathrm{gB}$ is the force free current, $\mathrm{V}$ is periodic in $\alpha$ and satisfies the magnetic differential equation, $\vec{B} \bullet \nabla V=1$, which is obtained by substituting Eq. (4) into Eq. (2). From $\nabla \cdot \overrightarrow{\mathbf{J}}=0, \vec{B} \bullet \nabla$ $\mathrm{g}=0$ and $\mathrm{g}$ is a field line constant. Since $\nabla \cdot \overrightarrow{\mathrm{J}}=0$ and $\overrightarrow{\mathbf{J}} \bullet \nabla \psi=0$, the current density can be written in the general form $\overrightarrow{\mathbf{J}}=\nabla \psi \times[\mathrm{G}(\psi) \nabla \alpha+\mathrm{T}(\psi) \nabla \chi+\nabla \lambda(\psi, \alpha, \chi)]$ [Shafranov, 1968], where $\lambda$ is periodic in both $\alpha$ and $\chi$, and from Eq.(4) we show that $g=g(\psi)$. Note that $g$ vanishes 
if there is a north-south or east-west symmetry. In the $(\psi, \alpha, \chi)$ flux coordinate system $\mathrm{dV}=\mathrm{ds} / \mathrm{B}$ $=d \mathrm{~d} \chi=\mathrm{d}^{3} \mathrm{x} /(\mathrm{d} \psi \mathrm{d} \alpha)$, where $\mathrm{ds}$ is the element of arc length along the magnetic field line. Thus, $\mathrm{V}$ has the physical meaning of the magnetic flux tube volume per unit flux. The magnetic differential equation can be integrated to give $\mathrm{V}(\psi, \alpha, \chi)=\mathrm{V}_{\mathrm{s}}(\psi, \alpha, \chi)+\mathrm{V}_{0}(\psi, \alpha)$, where $\mathrm{V}_{0}(\psi, \alpha)$ is an integration constant along the field line, and $\mathrm{V}_{\mathrm{s}}(\psi, \alpha, \chi)=\int J \mathrm{~d} \chi$ is an indefinite integral along the field line.

From Eq. (4) the field-aligned current density is given by $\mathrm{J}_{\mathbb{1}} / \mathrm{B}=-(\mathrm{dP} / \mathrm{d} \psi)(\partial \mathrm{V} / \partial \alpha)+$ $(\vec{d} \bullet \nabla \chi \times \nabla P) / B^{2}+g(\psi)$. For any two points 1 and 2 along the field line we have $\left(J_{\|} / \mathrm{B}\right)_{2}-$ $\left(\mathrm{J}_{\|} / \mathrm{B}\right)_{1}=-(\partial \mathrm{P} / \partial \psi)(\partial \mathrm{U} / \partial \alpha)+(\overrightarrow{\mathrm{B}} \bullet \nabla \chi \times \nabla \mathrm{P})_{2} / \mathrm{B}_{2}{ }^{2}-(\overrightarrow{\mathrm{B}} \bullet \nabla \chi \times \nabla \mathrm{P})_{1} / \mathrm{B}_{1}{ }^{2}$, where $\mathrm{U}(\psi, \alpha ; 1,2)$ $=\mathrm{V}_{\mathrm{S}}\left(\psi, \alpha, \chi_{2}\right)-\mathrm{V}_{\mathrm{S}}\left(\psi, \alpha, \chi_{1}\right)=\int_{\chi_{1}}^{\chi_{2}} \mathrm{~d} \chi$, and the subscripts 1 and 2 denote that the quantities are evaluated at $\chi_{1}$ and $\chi_{2}$, respectively. For three-dimensional magnetospheric equilibria with northsouth symmetry, $\mathrm{J}_{\|}=\overrightarrow{\mathrm{B}} \times \nabla \chi=0$ at the equator. Thus, the field-aligned current density at the ionosphere can be expressed in terms of the equatorial quantities as [Vasylinuas, 1970; Birmingham, 1992]

$$
\mathrm{J}_{\|_{\mathrm{i}}} / \mathrm{B}_{\mathrm{i}}=\overrightarrow{\mathrm{B}}_{\mathrm{e}} \times \nabla \mathrm{U}(\psi, \alpha ; \mathrm{e}, \mathrm{i}) \bullet \nabla \mathrm{P} / \mathrm{B}_{\mathrm{e}}{ }^{2}+(\overrightarrow{\mathrm{B}} \bullet \nabla \chi \times \nabla \mathrm{P})_{\mathrm{i}} / \mathrm{B}_{\mathrm{i}}{ }^{2}
$$

,where the subscripts e and $i$ denote that the quantities are evaluated at the equator and the ionosphere, respectively, and the gradients, $\nabla \mathrm{U}$ and $\nabla \mathrm{P}$, are taken at the equator. As pointed out by Birmingham [1992] the second term is missing in the expression given by Vasyliunas [1970], and it is much smaller than the first term by a factor of $\mathrm{L}^{-6}$ if we choose $\chi=\mathrm{s}$. Note that if there is an east-west symmetry, $\mathrm{J}_{\|}$is zero in the noon-midnight meridian plane.

From Eq. (4) we have $\boldsymbol{d \vec { j }} \cdot \nabla \chi=-(\mathrm{dP} / \mathrm{d} \psi)(\partial \mathrm{V} / \partial \alpha)$ if there is no force free current. Since $V$ is period in $\alpha, \int_{0}^{2 \pi} \mathrm{d} \alpha \vec{J} \cdot \nabla \chi=0$ and the total net poloidal current across a constant $\chi$ surface, $I_{p}=(1 / 2 \pi) \int d^{3} x \vec{j} \bullet \nabla \chi$, is zero. Therefore, there is no net poloidal current into the planetary ionosphere in the absence of the force free current.

\section{Numerical Results from the MAG-3D Code}


Equations (1) and (2) can be cast into inverse equilibrium equations in terms of a flux coordinate $(\psi, \alpha, \chi)$ system [Cheng, 1992]. A three-dimensional magnetospheric equilibrium code, the MAG-3D code, has been developed based on an iterative metric method for solving the coupled set of nonlinear inverse equilibrium equations. If we choose $\mathrm{ds} / \mathrm{d} \chi=\boldsymbol{J} \mathrm{B}=\mathrm{F}(\psi, \alpha)$, we have an equal arc length coordinate system. The numerical grid on which finite differences are evaluated is tied to the equilibrium solution itself in such a way that grid points automatically accumulate in regions of step gradients, thus yielding accurate solutions of high $\beta$ magnetospheric equilibria. An iterative metric method is used to solve for the discrete rectangular coordinate $[x(\psi, \alpha, \chi), y(\psi, \alpha, \chi)$, $\mathrm{z}(\psi, \alpha, \chi)]$ of constant $\psi$ and $\alpha$ surfaces such that the finite-differenced inverse equilibrium equations based on these points are satisfied to a small tolerance. The MAG-3D code is the first self-consistent three-dimensional magnetospheric equilibrium code.

In the paper we consider a fixed boundary problem. The computational domain is bounded by (1) an outer boundary with flux $\psi=\psi_{\text {out }}$ and with its shape specified to take into account the effect of the solar wind and the interplanetary magnetic field, (2) an inner boundary with $\psi=\psi_{\text {in }}$ which is mainly determined by the dipole magnetic field, and (3) the Earth's surfaces between $\psi_{\text {in }}$ and $\psi_{\text {out }}$ curves. The boundary condition on the Earth's surface is $\alpha=\phi$. In the computational domain, a $(\rho, \alpha, \chi)$ flux coordinate is chosen with $0 \leq \chi \leq \pi, 0 \leq \alpha \leq 2 \pi$, and $0 \leq \rho \leq 1$, where $\psi$ $=\psi(\rho)$ is chosen such that uniform $\rho$ grids give optimal equatorial radial grids for the computational purpose. The equatorial dipole magnetic field intensity is $B_{D}$ at $R=R_{0}$. The magnetic flux is chosen to be $\psi_{\text {out }} \equiv-B_{D} R_{o}{ }^{3} / R_{\max }$ at the outer magnetic surface and $\psi_{\text {in }} \equiv-B_{D}$ $R_{0}{ }^{3} / R_{\min }$ at the inner magnetic surface. In a right-handed $(r, \phi, \theta)$ spherical coordinate system with $\theta=-\pi / 2,0, \pi / 2$ corresponding to the south pole, the equator, and the north pole, respectively, the shape of the outer flux surface is specified by choosing $\psi_{\text {out }}=-B_{D} R_{o}^{3} \cos ^{2} \theta / r$ $+\left[B_{C}\left(r-R_{E}\right) \cos ^{2} 2 \theta+B_{S}\left(r-R_{E}\right)^{2} \sin ^{2} 3 \theta\right] \cos \phi$, and the inner flux surface shape is specified by choosing a dipole field surface, $\psi_{\text {in }}=-B_{D} R_{0}{ }^{3} \cos ^{2} \theta / r$. Note that $B_{C}$ and $B_{S}$ determine the outer flux surface shape which has a significant effect on the magnetospheric equilibrium. For $\mathrm{B}_{\mathrm{C}}$ $>0$ and $\mathrm{B}_{\mathrm{S}}<0$, the outer flux boundary is compressed on the dayside due to solar wind pressure, and resembles a stretched tail-like surface on the nightside. The pressure profile is chosen to be $\mathrm{P}(\psi)=\mathrm{P}_{\mathrm{o}}\left[\left(\psi_{2}-\psi\right) / \gamma\right]^{\gamma}\left[\left(\psi-\psi_{1}\right) / \nu\right]^{\nu}\left[(\gamma+v) /\left(\psi_{2}-\psi_{1}\right)\right]^{\gamma+\nu}$. The following numerical results are obtained with $R_{0}=6.6 R_{E}, R_{\min }=2 R_{E}, R_{\max }=10 R_{E}, \gamma=2, v=2, B_{D}=1, \psi_{1}=\psi_{\text {in }}$, and $\psi_{2}$ $=\psi_{\text {out }}$. These parameters are reasonable to model the basic features of the magnetospheric equilibria.

Numerical examples that illustrate qualitative equilibrium features of an isotropic pressure magnetosphere with north-south as well as east-west symmetries are given. Figures 1 shows the 
flux surfaces in the noon-midnight meridian plane. The computation is performed for $P_{o}=0.6$ with 65 flux surfaces and 65 poloidal angle grid points and 65 toroidal angle grid points. The outer boundary flux shape is specified by $\mathrm{B}_{\mathrm{C}}=0.7, \mathrm{~B}_{\mathrm{S}}=-0.05$ so that the outer flux surfaces are compressed to $R \approx 8.43 \mathrm{R}_{\mathrm{E}}$ on the dayside and stretch out to $R \approx 15.39 \mathrm{R}_{\mathrm{E}}$ on the nightside. The solid lines correspond to the equilibrium constant $\psi$ surfaces, and the dotted lines represent the corresponding dipole magnetic flux surfaces. In the low beta region with $\mathrm{L}<4$ the flux surfaces are similar to the dipole surfaces, but for $\mathrm{L}>4$ the flue surfaces are greatly distorted by the combined effects of finite $\beta$ and the boundary flux shape. The effect of finite $\beta$ is to expand the flux surface outward toward the lower magnetic field region. The effect of the outer flux shape is to compress the flux surfaces inward on the dayside and to stretch the flux surfaces outward on the nightside. Along the midnight equatorial line the pressure is peaked at $R \approx 3.3 R_{E}$. But, the peak beta is at $R \approx 11.2 R_{E}$ and is about 2.25. These three-dimensional results, as well as the radial variation of the plasma pressure $P$, the plasma $\beta$, the toroidal ring current $J_{\phi}$, and the fractional difference between the self-consistent magnetic field and dipole field, $\left(\mathrm{B}-\mathrm{B}_{\mathrm{D}}\right) / \mathrm{B}_{\mathrm{D}}$, in the equatorial plane, are similar to the two-dimensional axisymmetric results [Cheng, 1992] obtained with the same boundary flux surface shape at each local time cross section.

The main difference between the three-dimensional and two-dimensional axisymmetric results is that the field-aligned current and the toroidal magnetic field are finite for the threedimensional case, but vanish for the two-dimensional axisymmetric case. Fig. 2 shows a quadrant of the outer $\left(\psi=\psi_{\text {out }}\right)$ flux surface with the magnetic field lines shown by the blue lines and the constant toroidal angle lines shown by the red lines. On the noon-midnight meridian plane as well as the equatorial plane the magnetic field does not have a toroidal component. Near the equatorial plane on the northern hemisphere the magnetic field has a toroidal component pointing toward the midnight direction on the nightside and pointing toward the noon direction on the dayside. From Eq.(3) the toroidal magnetic field provides a magnetic drift across the pressure gradient and gives rise to the field-aligned current. Figure 3 shows the constant field-aligned current density contours over the northern polar region. The solid contour curves represent $J_{\|}>0$ and the dotted contour curves represent $J_{\|}<0$. On the noon-midnight and equatorial planes, $J_{\|}=0$. Thus, on the dusk side of the Earth's northern polar ionosphere, the field-aligned current density is positive (flowing into the ionosphere) for higher latitude flux surfaces where $\mathrm{dP} / \mathrm{d} \psi<0$. The field-aligned current localizes in the region between $60^{\circ}$ and $70^{\circ}$ latitudes, and its density is peaked at about $66^{\circ}$ in latitude and at 23:00 local time. The field-aligned current system is in the opposite direction on the dawn side of the Earth northern pole. These are similar to the observed region 2 current [Iijima and Potemra, 1976a,b]. 


\section{Discussion}

The MAG-3D code results presented in the paper represent the first self-consistent solution of the three-dimensional magnetospheric equilibrium with isotropic pressure. A natural extension is to consider the pressure anisotropy effect. In order to provide a more conclusive test of the magnetospheric equilibrium calculations with satellite observations, detail information of ring current particle distribution (pressure anisotropy) and better boundary conditions may be required. For the information of particle distributions, issues related to the sources and composition of ring current particles as well as energization and injection processes associated with the storm time ring current formation need to be resolved. For the boundary conditions, we shall explore a more complicated form of the outer flux surface such as empirical shapes from the magnetic field models [Tsyganenko, 1987, 1989], which is obtained by considering all the major magnetospheric current systems outside the magnetopause. To determine the outer magnetic flux surface (magnetopause) self-consistently, the shape of the magnetopause will be determined iteratively as part of the equilibrium solution by a force balance between the magnetic field and a steady solar wind with the requirement that the normal component of the magnetic field vanish at the boundary.

\section{Acknowledgments}

This work is supported by the NASA Grant No. W-18,329 and DoE Contract No. DEAC02-76-CHO3073. The author would like to thank Drs. V. V. Drozdov and D. Monticello for useful discussions. In particular, the author would like to thank Dr. Drozdov for helping the study with the POLAR-3D code [Degtyarev et al., 1987] that solves three-dimensional MHD equilibrium equations by assuming nested and closed flux surfaces and by employing prescribed poloidal and toroidal angle coordinates.

\section{References}

Akasofu, S. -I., and S. Chapman, The ring current, geomagnetic disturbance, and the Van Allen radiation belts, J. Geophys. Res., 66, 1321, 1961.

Birmingham, T. J., Birkeland currents in an anisotropic, magnetostatic plasma, J. Geophys. Res., 97, 3907, 1992.

Birn, J., Magnetotail equilibrium theory: The general three-dimensional solution, J. Geophys. Res., 92, 11101, 1987.

Cheng, C. Z., Magnetospheric equilibrium with anisotropic pressure, J. Geophys. Res., 97, 1497, 1992. 
Degtyarev, L. M., V. V. Drozdov, Yu. Yu. Poshekhonov, The new finite-difference code POLAR-3D and some results of its application to calculating the MHD equilibrium and stability of plasma in 3D closed configurations, 14th European Conference on Controlled Fusion and Plasma Physics (Madrid, 1987), Vol. 11D, Part 1, p. 377-380.

Heinemann, M., and D. H. Pontius, Jr., Representations of currents and magnetic fields in isotropic magnetohydrostatic plasma, J. Geophys. Res., 95, 251, 1990.

Iijima, T., and T. A. Potemra, The amplitude distribution of field-aligned currents at northern high latitudes observed by Triad, J. Geophys. Res., 81, 2165, 1976a.

Iijima, T., and T. A. Potemra, Field-aligned currents in the dayside cusp observed by Triad, J. Geophys. Res., 81, 5971, 1976 b.

Schindler, K., and J. Birm, Magnetospheric physics, Phys. Rep., 47, 110, 1978.

Shafranov, V. D., Flute instability in a current-carrying curved plasma column, Nuclear Fusion, 8 , 253, 1968, Eq.(9).

Tsyganenko, N. A., Global quantitative models of the geomagnetic field in the cislunar magnetosphere for different disturbance levels, Planet. Space Sci., 35, 1347, 1987.

Tsyganenko, N. A., A magnetospheric magnetic field model with a warped tail current sheet, Planet. Space Sci., 37, 5, 1989.

Vasyliunas, V. M., Mathematical models of magnetospheric convection and its coupling to the ionosphere, edited by B. M. McCormac, p. 60, D. Reidel, Hingham, Mass., 1970.

\section{Figure Captions}

Fig. 1 The constant $\psi$ surfaces of a three-dimensional magnetospheric equilibrium with isotropic pressure with $\mathrm{P}_{\mathrm{o}}=0.6, \mathrm{~B}_{\mathrm{C}}=0.7, \mathrm{~B}_{\mathrm{S}}=-0.05$ in the noon-midnight meridian plane. The solid lines correspond to the magnetic field lines and the dotted lines correspond to the dipole field surfaces.

Fig. 2 A quadrant of the outer $\left(\psi=\psi_{\text {out }}\right)$ flux surface with same parameters as in Fig. 1. The magnetic field lines (with the magnetic field pointing upward) are shown as blue lines and the constant toroidal angle lines are shown as red lines.

Fig. 3 The field-aligned current density contours at the ionosphere boundary over the northern pole with same parameters as in Fig. 1. The solid (dotted) contour curves represent field aligned current density flowing into (out of) the ionosphere. 


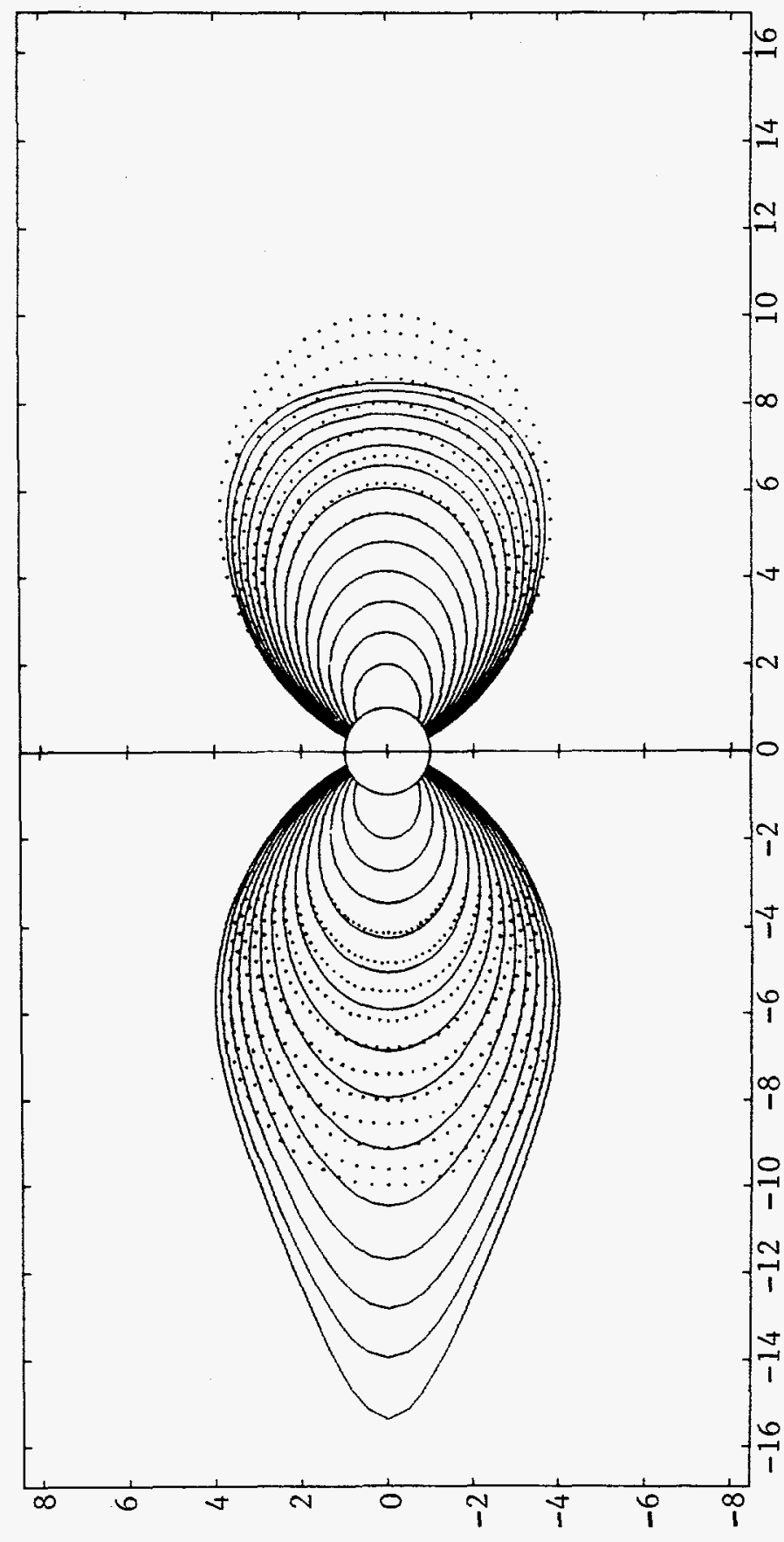

$\underset{\substack{a 0 \\ i=1}}{\overrightarrow{0}}$

$N$ 


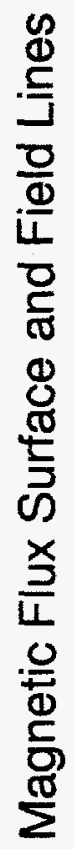

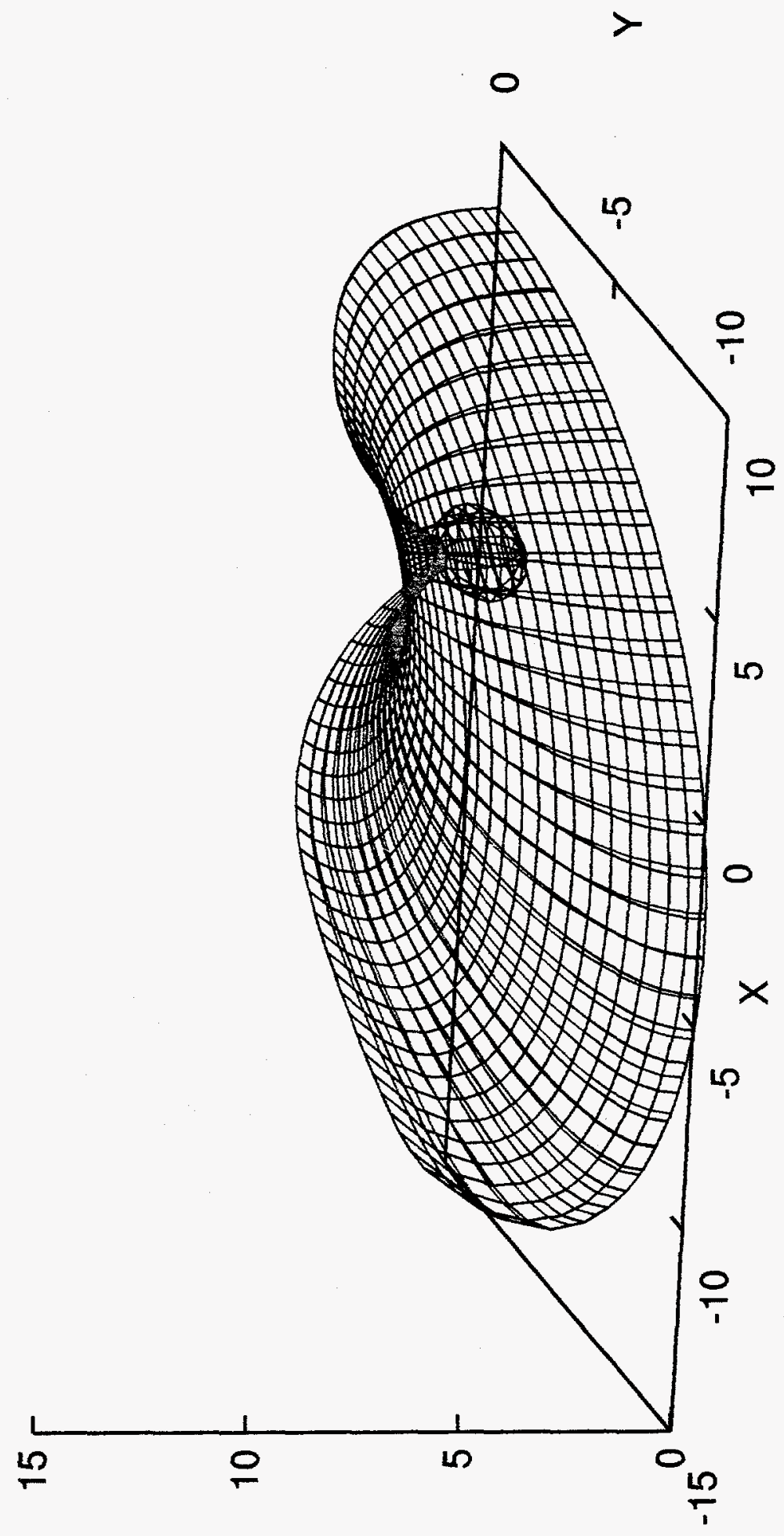




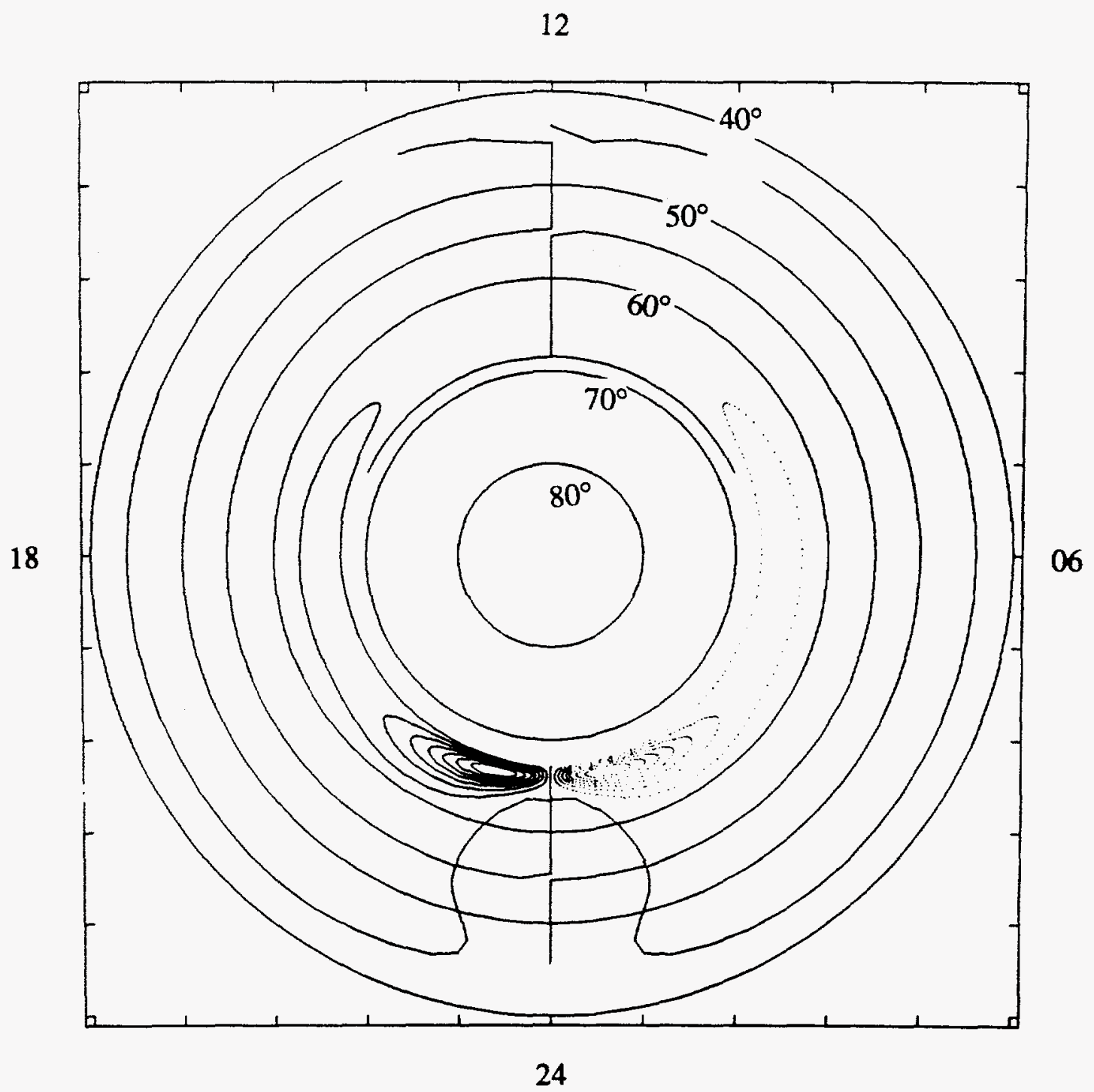

Fig. 3 
Dr. F. Paoloni, Univ. of Wollongong, AUSTRALIA

Prof. R.C. Cross, Univ. of Sydney, AUSTRALIA

Plasma Research Lab., Australian Nat. Univ., AUSTRALIA

Prot. I.R. Jones, Flinders Univ, AUSTRALIA

Prof. F. Cap, Inst. for Theoretical Physics, AUSTRIA

Prof. M. Heindler, Institut für Theoretische Physik, AUSTRIA

Prof. M. Goossens, Astronomisch Instituut, BELGIUM

Ecole Royale Militaire, Lab. de Phy. Plasmas, BELGIUM

Commission-European, DG. XII-Fusion Prog., BELGIUM

Prof. R. Bouciqué, Rijksuniversiteit Gent, BELGIUM

Dr. P.H. Sakanaka, Instituto Fisica, BRAZIL

Prof. Dr. I.C. Nascimento, Instituto Fisica, Sao Paulo, BRAZIL Instituto Nacional De Pesquisas Espaciais-INPE, BRAZIL

Documents Office, Atomic Energy of Canada Ltd., CANADA

Ms. M. Morin, CCFWTokamak de Varennes, CANADA

Dr. M.P. Bachynski, MPB Technologies, Inc., CANADA

Dr. H.M. Skarsgard, Univ. of Saskatchewan, CANADA

Prot. J. Teichmann, Univ. of Montreal, CANADA

Prof. S.R. Sreenivasan, Univ. of Calgary, CANADA

Prof. R. Marchand, INRS-Energie et Materiaux, CANADA

Dr. R. Bolton, Centre canadien de fusion magnétique, CANADA

Dr. C.R. James, Univ. of Alberta, CANADA

Dr. P. Lukác, Komenského Universzita, CZECHO-SLOVAKIA

The Librarian, Culham Laboratory, ENGLAND

Library, R61, Rutherford Appleton Laboratory, ENGLAND

Mrs. S.A. Hutchinson, JET Library, ENGLAND

Dr. S.C. Sharma, Univ. of South Pacific, FIJI ISLANDS

P. Mähönen, Univ. of Helsinki, FINLAND

Prof. M.N. Bussac, Ecole Polytechnique, FRANCE

C. Mouttet, Lab. de Physique des Milieux lonisés, FRANCE

J. Radet, CEN/CADARACHE - Bat 506, FRANCE

Prof. E. Economou, Univ. of Crete, GREECE

Ms. C. Rinni, Univ. of loannina, GREECE

Preprint Library, Hungarian Academy of Sci., HUNGARY

Dr. B. DasGupta, Saha Inst. of Nuclear Physics, INDIA

Dr. P. Kaw, inst. for Plasma Research, INDIA

Dr. P. Rosenau, Israel Inst of Technology, ISRAEL

Librarian, Intemational Center for Theo Physics, ITALY

Miss C. De Palo, Associazione EURATOM-ENEA, ITALY

Dr. G. Grosso, Istituto di Fisica del Plasma, ITALY

Prof. G. Rostangni, Istituto Gas lonizzati Del Cnr, ITALY
Dr. H. Yamato, Toshiba Res \& Devel Center, JAPAN

Prof. I. Kawakami, Hiroshima Univ., JAPAN

Prof. K. Nishikawa, Hiroshima Univ., JAPAN

Librarian, Naka Fusion Research Establishment, JAERI, JAPAN

Director, Japan Atomic Energy Research Inst., JAPAN

Prof. S. Itoh, Kyushu Univ., JAPAN

Research Info. Ctr., National Instit. for Fusion Scienć, JAPAN

Prof. S. Tanaka, Kyoto Univ., JAPAN

Library, Kyoto Univ., JAPAN

Prof. N. Inove, Univ. of Tokyo, JAPAN

Secretary, Plasma Section, Electrotechnical Lab., JAPAN

Dr. O. Mitarai, Kumamoto Inst. of Technology, JAPAN

Dr. G.S. Lee, Korea Basic Sci. Ctr., KOREA

J. Hyeon-Sook, Korea Atomic Energy Research Inst., KOREA

D.I. Choi, The Korea Adv. Inst. of Sci. \& Tech., KOREA

Leandro Melendez Lugo, Inst. Nac1. de Inves. Nucl, MEXICO

Prof. B.S. Liley, Univ. of Waikato, NEW ZEALAND

Inst of Physics, Chinese Acad Sci PEOPLE'S REP. OF CHINA

Library, Inst. of Plasma Physics, PEOPLE'S REP. OF CHINA

Tsinghua Univ. Library, PEOPLE'S REPUBLIC OF CHINA

Z. Li, S.W. Inst Physics, PEOPLE'S REPUBLIC OF CHINA

Prof. J.A.C. Cabral, Instituto Superior Tecnico, PORTUGAL

Prof. M.A. Hellberg, Univ. of Natal, S. AFRICA

Prof. D.E. Kim, Pohang inst. of Sci. \& Tech., SO. KOREA

Prof. C.I.E.M.A.T, Fusion Division Library, SPAIN

Dr. L. Stenflo, Univ. of UMEA, SWEDEN

Library, Royal Inst. of Technology, SWEDEN

Prof. H. Withelmson, Chalmers Unis. of Tech., SWEDEN

Centre Phys. Des Plasmas, Ecole Polytech, SWITZERLAND

Bibliotheek, Inst. Voor Plasma-Fysica, THE NETHERLANDS

Asst. Prof. Dr. S. Cakir, Middle East Tech. Univ., TURKEY

Dr. V.A. Glukhikh,Sci. Res. Inst. Electrophys.I Apparatus, USSR

Dr. D.D. Ryutov, Siberian Branch of Academy of Sa., USSR

Dr. G.A. Eliseev, I.V. Kurchatov Inst., USSR

Librarian, The Ukr.SSR Academy of Sciences, USSR

Dr. L.M. Kovrizhnykh, Inst. of General Physics, USSR

Kemforschungsanlage GmbH, Zentralbibliothek, W. GERMANY

Bibliothek, Inst. Für Plasmaforschung, W. GERMANY

Prol. K. Schindler, Ruhr-Universitát Bochum, W. GERMANY

Dr. F. Wagner, (ASDEX), Max-Planck-Institut, W. GERMANY

Librarian, Max-Planck-Institut, W. GERMANY 